\title{
AMELIORATIVE EFFECT OF CYPERUS SQUARROSUS (CYPERACEAE) PLANT EXTRACTS ON DIABETIC CARDIOMYOPATHY AGAINST STREPTOZOTOCININDUCED DIABETES IN WISTAR RATS
}

\author{
RAGHAVENDRA HG ${ }^{1 *}$, RAVI PRAKASH P², DEVANNA N ${ }^{3}$ \\ ${ }^{1}$ Research Scholar, Department of Pharmaceutical Sciences, Jawaharlal Nehru Technological University, Ananthapuramu, Andhra Pradesh, \\ India. ${ }^{2}$ Professor, Department of Pharmaceutics, Creative Educational Society's College of Pharmacy, Kurnool, Andhra Pradesh, India. \\ ${ }^{3}$ Professor, Department of Chemistry and Director, Oil Technological and Pharmaceutical Research Institute, Ananthapuramu, \\ Andhra Pradesh, India. Email: raghuspsp@gmail.com \\ Received: 15 April 2020, Revised and Accepted: 25 May 2020
}

Objective: Cyperus squarrosus, belongs to the family Cyperaceae, has been claimed to possess antidiabetic activity in the ethnomedicinal literature in India. Therefore, the present study was to investigate the effects of aqueous and ethanolic extracts of C. squarrosus (EECS) on diabetes and its cardiovascular complications with streptozotocin-induced diabetes in rats.

Methods: Wister albino rats of either sex were made diabetic with streptozotocin ( $65 \mathrm{mg} / \mathrm{kg}$, i.v.). Glibenclamide ( $5 \mathrm{mg} / \mathrm{kg}$ ) was taken as standard drug. Treatment of aqueous and EECS (aqueous extract of C. squarrosus and EECS) was given in the dose of 200 and $400 \mathrm{mg} / \mathrm{kg} / \mathrm{day}$, p.o for 8 weeks and biochemical (serum glucose, cholesterol, triglycerides, and high-density lipoprotein [HDL]) parameters were recorded.

Results: Streptozotocin-treated group produced significant increased levels of serum glucose, cholesterol, triglycerides, HDL, creatine kinase-myocardial band (CK-MB), and lactate dehydrogenase (LDH) levels and all these changes were prevented by the treatment with aqueous and EECS in both doses.

Conclusion: As compare with ethanolic extract treated group, aqueous extract treated group exhibits significant ( $\mathrm{p}<0.001$ ) effect on CK-MB and LDH levels. Our result suggests that aqueous and EECS prevents the streptozotocin-induced metabolic abnormalities as well as cardiovascular complications.

Keywords: Cyperus squarrosus, Streptozotocin, Diabetic, Glibenclamide, Cardiovascular complications.

(c) 2020 The Authors. Published by Innovare Academic Sciences Pvt Ltd. This is an open access article under the CC BY license (http://creativecommons. org/licenses/by/4. 0/) DOI: http://dx.doi.org/10.22159/ajpcr.2020.v13i7.37927

\section{INTRODUCTION}

Diabetes mellitus (DM) is a chronic metabolic syndrome characterized by elevated levels of blood glucose, which may be attributed to abnormal insulin discharge and/or insulin resistance. The disease has a major impact on the quality of life in the financial, psychological, and physical sectors [1]. The incidence of DM has risen exponentially in recent decades, and by 2025, the number of people with diabetes is estimated at $330-380$ million. It is known that diabetes is a potent and prevalent risk factor for ischemic heart disease. For the 3.8 million deaths annually, $\sim 2 / 3$ are due to diabetes complicated heart disease [2]. Diabetic cardiomyopathy (DCM), associated with both type 1 and type 2 diabetes, is one of the main cardiovascular complications in diabetic patients and is characterized by both early diastolic and late systolic dysfunctions that may trigger cardiac insufficiency $[3,4]$. Through DCM pathogenesis, multiple pathways were associated. The pathophysiological mechanisms include metabolic-altered substrate metabolism, microvascular dysfunction, activation of the reninangiotensin-aldosterone system, oxidative stress, apoptosis of the cardiomyocyte, mitochondrial failure, and impaired handling of $\mathrm{Ca}^{2+}[5]$. The prevalence of diabetes problems and minimal available therapeutic options has led to an intense interest in successful medicinal plants in diabetic syndrome care. Some plants have already confirmed that green tea mitigates DCM cardiac dysfunction [6]. Investigations with Citrullus colocynthis have shown improved enzyme homeostasis and end-organ function [7] and protective role of Embelia ribes fruit extract (Myrsinaceae) in isoproterenol-induced cardiotoxicity in diabetic rats [8]. Cyperus squarrosus is a little sedge of family Cyperaceae genus Cyperus. Plant reaching a maximum height between 10 and $16 \mathrm{~cm}$.
There are one to three short, thin leaves around the base of the plant of Cyperaceae family, all parts of the plant contain alkaloids, steroids, triterpenes, flavonoids, tannins, and phenylethanoid glycosides. Since it was reported that the selected plant species were endowed with both antidiabetic and anti-inflammatory behaviors, the present investigation was conducted to estimate the protective impact of $C$. squarrosus on diabetics and its collaborative pathogenesis in cardiac tissues. Streptozotocin (STZ)-induced diabetic model on experimental rats was chosen for this study.

\section{METHODS}

Plant material and authentication

Plant was collected from Tirumala hills, authenticated by Professor Dr. K. Madhava Chetty, HOD, Department of Botany at the University of S V University, Tirupati, AP., and a voucher specimen (V. No 2296) was prepared and deposited at the S V University. The collected plant was cleaned and washed well with water. Plant was dried under shade drying and grinded well to coarse powder. Coarse powder was stored in an airtight container with labeling and it is used for further experimentation.

\section{Preparation of extract}

Aqueous extract of C. squarrosus (AECS)

The powder was macerated in the distilled water in a ratio of 1:10 (W/V) for $48 \mathrm{~h}$. The mixture was filtered and concentrated in the oven at $55^{\circ} \mathrm{C}$ for until dryness and percentage of yield was calculated (11.03\%). Two drops of chloroform were added to the extract and stored in airtight bottle. 
Ethanolic extract of C. squarrosus (EECS)

The ethanol extract was prepared using Soxhlet apparatus. The solvent was evaporated under reduced pressure in rotary evaporator to semisolid consistency and percentage of yield was calculated (12.1\%). Two drops of chloroform were added to the extract and stored in airtight bottle.

\section{Acute toxicity studies}

An experiment was conducted to find whether an extracts are deliver any toxic sign and dose selection on normal rats. Thirty normal healthy Wister rats starved for $12 \mathrm{~h}$ were randomly divided into 10 groups $(\mathrm{n}=3)$ and given orally with AECS and EECS beginning with a fixed dose of 500 , $1000,1500,2000$, and $5000 \mathrm{mg} / \mathrm{kg}$ body weight (b.w.) for each extract. Animals were individually dosed and constantly tracked for $8 \mathrm{~h}$ on the $1^{\text {st }}$ day and 14 days later, their behavioral and neurological parameters were observed for signs of acute toxicity; a dose of $2000 \mathrm{mg} / \mathrm{kg}$ was evaluated in conformance with guidelines 423 of the Organization for Economic Cooperation and Development (OECD). Selection of two doses of the drug $\left(1 / 10^{\text {th }}\right.$ and $\left.1 / 5^{\text {th }}\right)$ was made on the basis of an acute toxicity test. All rats were fed a normal diet of pellets and tap water $a d$ libitum and mortality caused by the extracts was also observed during this time frame.

\section{Experimental animals}

In the present study, Wistar rats (180-200 g) of both sexes were used. The animals were kept in cages under natural light and dark cycle and were acclimatized to laboratory conditions (environmental temperature) in the central animal house facility of CES College of Pharmacy, for 7 days before the start of the experiments. Animals were served a normal diet of rodents and water ad libitum. The experimental protocol was duly approved by the Institutional Animal Ethical Committee and care of animals was carried out as per the guidelines of Committee for the Purpose of Control and Supervision of Experiments on Animals, India (1305/Po/Re/S/09/CPCSEA).

\section{Induction of diabetes in rats}

The rats were fasted for $18 \mathrm{~h}$, and diabetes was induced by a single intravenous injection of freshly prepared STZ solution $(65 \mathrm{mg} / \mathrm{kg}$ b.w.) in $0.1 \mathrm{M}$ citrate buffer ( $\mathrm{pH} 4.5$ ) induced diabetes. The animals were permitted to drink $5 \%$ glucose solution to protect them from STZs diabetogenic action and then kept fasting to avoid excessive accumulation of feeding glucose that could antagonize STZ effect. Control rats were injected with citrate buffer alone. After $72 \mathrm{~h}$ of injection, fasting blood glucose level was checked, and animals with levels above $220 \mathrm{mg} / \mathrm{dl}$ were considered diabetic animals [9].

\section{Experimental design}

Diabetic animals were divided into six groups, each group contains eight animals. Animals untreated with STZ were kept in normal control (NC) group. Treatment was continued for 8 weeks as per the following plan for various groups.

Group I: NC was given blank acacia suspension ( $1 \mathrm{ml} / \mathrm{kg}$, p.o), daily for 8 weeks

Group II: Diabetic control (DC): Blank acacia suspension (1 ml/kg, p.o), daily for 8 weeks

Group III: Standard treatment (Std.): Glibenclamide ( $5 \mathrm{mg} / \mathrm{kg}$ b.w, p.o), daily for 8 weeks

Group IV: Test 1: Plant aqueous extract (200 mg/kg b.w, p.o.), daily for 8 weeks

Group V: Test 2: Plant aqueous extract ( $400 \mathrm{mg} / \mathrm{kg}$ b.w, p.o.), daily for 8 weeks

Group VI: Test 3: Plant ethanolic extract (200 mg/kg b.w, p.o.), daily for 8 weeks
Group VII: Test 4: Plant ethanolic extract (400 mg/kg bw p.o.), daily for 8 weeks

The major symptom of diabetic complications develops over a period of 1 month, i.e., 30-48 days (after 30 days of STZ administration)

The blood samples were drawn on initial day and $2^{\text {nd }}, 4^{\text {th }}, 6^{\text {th }}$, and $8^{\text {th }}$ weeks from the retro-orbital venous plexus of rats under ether anesthesia using a glass capillary tube after a fast of $12 \mathrm{~h}$ and the blood was centrifuged (3000 rpm/15 min) to get serum. The serum was used for biochemical estimation of blood glucose, triglycerides, cholesterol, and high-density lipoprotein (HDL)

Effect on DCM was evaluated by measuring serum creatine kinasemyocardial band (CK-MB) and lactate dehydrogenase (LDH) levels at $4^{\text {th }}$, $7^{\text {th }}$, and $8^{\text {th }}$ weeks and heart was isolated for histopathological studies at end day of the study. Heart was isolated at end of the experiment and weight was measured.

\section{Histopathological examination}

Isolated organs (heart) from normal and experimental rats were fixed in buffered formalin $(10 \%)$ and processed for paraffin sectioning. Sections obtained (approx. $5 \mu \mathrm{m}$ ) were stained by hematoxylin and eosin to study the histology of isolated organs [10].

Statistical analysis

All the data were expressed as mean \pm SEM. The one-way analysis of variance followed by Tukey's multiple comparison test or by unpaired Student's t-test using GraphPad Prism 5.0. The values are considered statistically significant when $\mathrm{p}<0.05$.

\section{RESULTS}

\section{Acute toxicity studies}

The aqueous and ethanol extract of $C$. squarrosus did not show any mortality and toxic manifestations up to the dose of $2000 \mathrm{mg} / \mathrm{kg}$. b.w. Based on the OECD 423 guidelines, the $1 / 10^{\text {th }}$ and $1 / 5^{\text {th }}$ dose as $200 \mathrm{mg} / \mathrm{kg}$ and double dose $400 \mathrm{mg} / \mathrm{kg}$ have been selected as the therapeutic doses for both extracts.

\section{Effect of AECS and EECS on serum biochemical parameters}

A single intraperitoneal injection of STZ (65 mg/kg b.w.) showed a substantial rise in glucose, triglycerides, cholesterol, and low-density lipoprotein (LDL) levels in DC rats relative to $\mathrm{NC}$ rats $(\mathrm{p}<0.001)$. Diabetic-induced rats administered with AECS and EECS (200 and $400 \mathrm{mg} / \mathrm{kg} \mathrm{b.w.)}$ for 8 weeks significantly decreased the serum glucose, triglycerides, cholesterol, and LDL level when compared with DC rats $(\mathrm{p}<0.001)$, whereas AECS $(400 \mathrm{mg} / \mathrm{kg}$ ) has shown significant decrease in blood glucose level as compared to Group-IV,V, and VI. DC significantly decreased the elevated HDL level when compared with Group-1 $(\mathrm{p}<0.001)$, whereas AECS $(400 \mathrm{mg} / \mathrm{kg})$ has shown significant increase in HDL level as compared to Group-IV, V, and VI. All the parameters studied are shown in Figs. 1-4.

\section{Effect of AECS and EECS on Cardiomyopathy}

A single intraperitoneal injection of STZ (65 mg/kg b.w.) group showed significant increase in CK-MB and LDH when compared with normal Group-1 ( $\mathrm{p}<0.001)$. Diabetic rats treated with AECS and EECS $(200$ and $400 \mathrm{mg} / \mathrm{kg} \mathrm{b} / \mathrm{w}$ ) for 8 weeks significantly decreased the CK-MB and LDH level when compared with DC rats $(\mathrm{p}<0.001)$, whereas AECS $(400 \mathrm{mg} / \mathrm{kg}$ ) has shown that significant decreased level was observed as compared to Group-IV, V, and VI. All the parameters studied are shown in Figs. 5-8.

\section{DISCUSSION}

Oral administration of AECS and EECS (200 and $400 \mathrm{mg} / \mathrm{kg} /$ day) significantly reduced the serum glucose levels and produced elevation in the serum insulin levels of STZ diabetic rats. Phytochemical investigations of $C$. squarrosus have exposed the presence of flavonoids, 


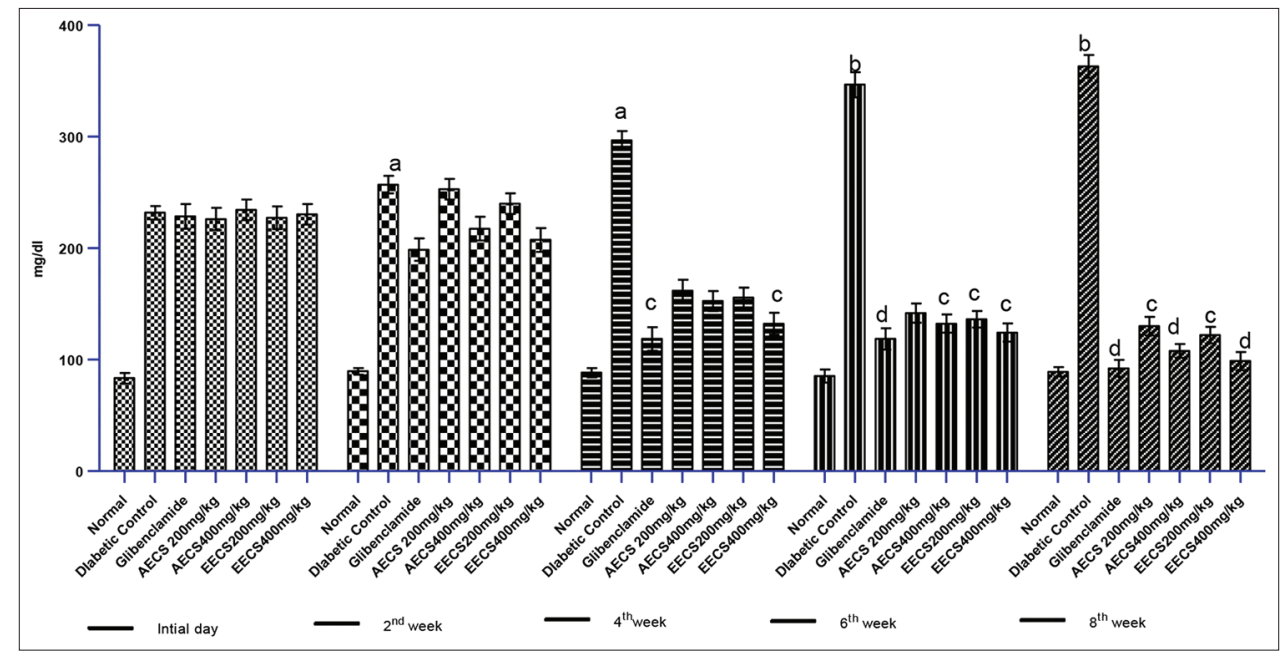

Fig. 1: Effect of plant extract on serum glucose levels. $a=p<0.01$, when compared to normal (Group-I), $b=p<0.001$, when compared to normal (Group-I), $c=p<0.05$, when compared to control (Group-II), $d=p<0.001$, when compared to control (Group-II)

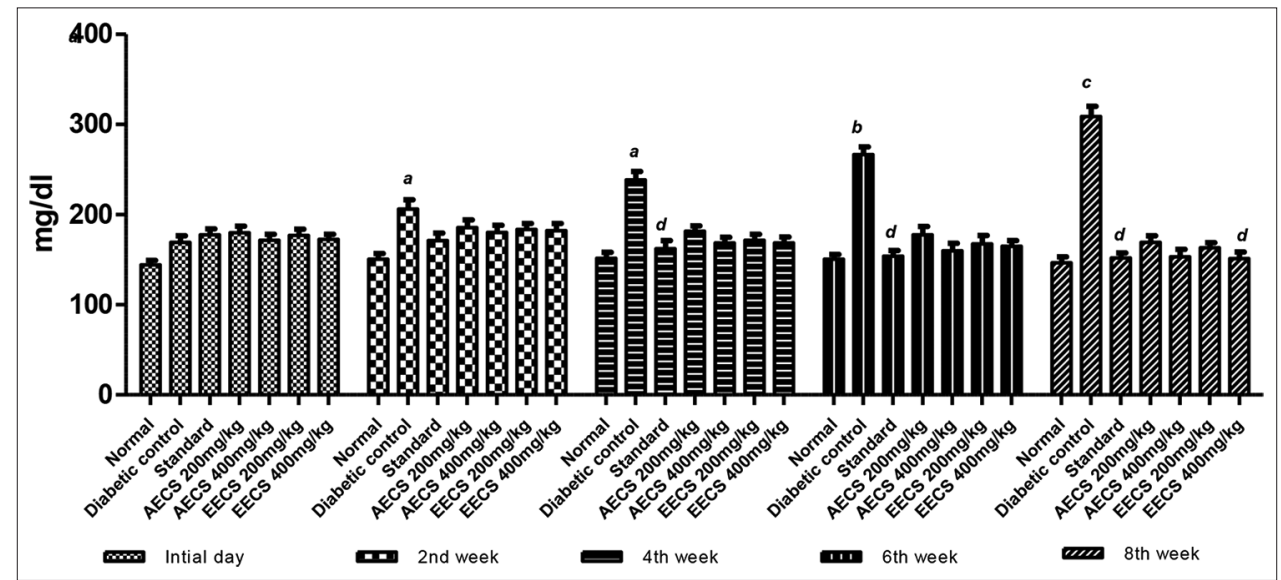

Fig. 2: Effect of plant extract on serum glyceride levels. $a=p<0.05$, when compared to normal (Group-I), $b=p<0.01$, when compared to normal (Group-I), $c=p<0.001$, when compared to normal (Group-I), $d=p<0.001$, when compared to control (Group-II)

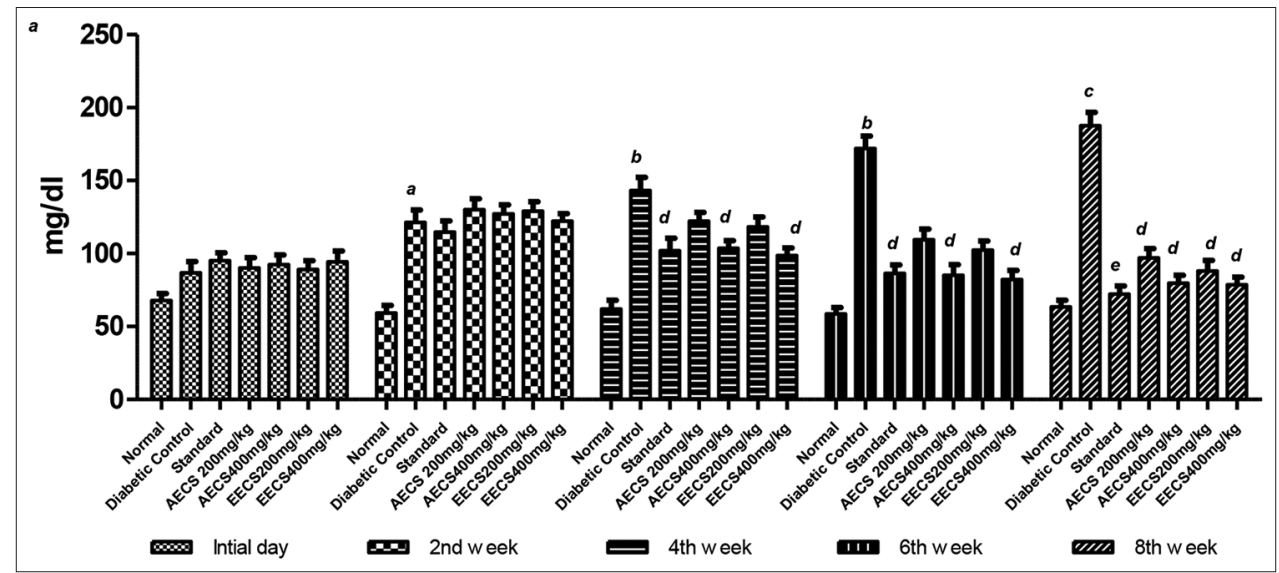

Fig. 3: Effect of plant extract on cholesterol levels. $a=p<0.05$, when compared to normal (Group-I), $b=p<0.01$, when compared to normal (Group-I), $c=p<0.001$, when compared to normal (Group-I), $\mathrm{d}=\mathrm{p}<0.001$, when compared to control (Group-II)

saponins, glycosides, terpenoids, and sterols [11]. Due to the presence of flavonoids may be responsible for the antidiabetic property. The flavonoids are a group of compounds that exhibit potential antioxidant properties that might protect pancreatic islets and help in $\beta$-cell regeneration, which in effect can contribute to improved levels of insulin. Moreover, flavonoids have their effect either by promoting glucose entry into cells, thereby stimulating glycolytic enzymes and glycogenic enzymes [12] or by inhibiting glucose-6-phosphatein the liver, consequently reducing the release of glucose in the blood. Increased insulin levels could be due to the stimulatory effect of rutin, 


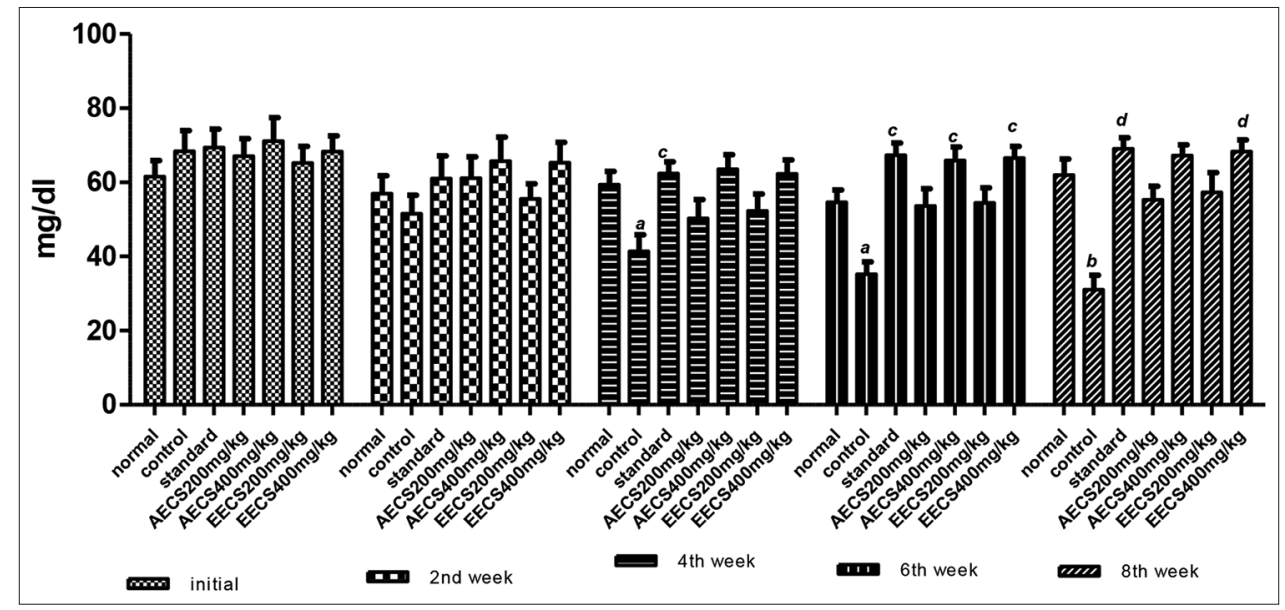

Fig. 4: Effect of plant extract on serum high-density lipoprotein levels. $a=p<0.01$, when compared to normal (Group-I), $b=p<0.001$, when compared to normal (Group-I), $c=p<0.01$, when compared to control (Group-II), $d=p<0.001$, when compared to control (Group-II)

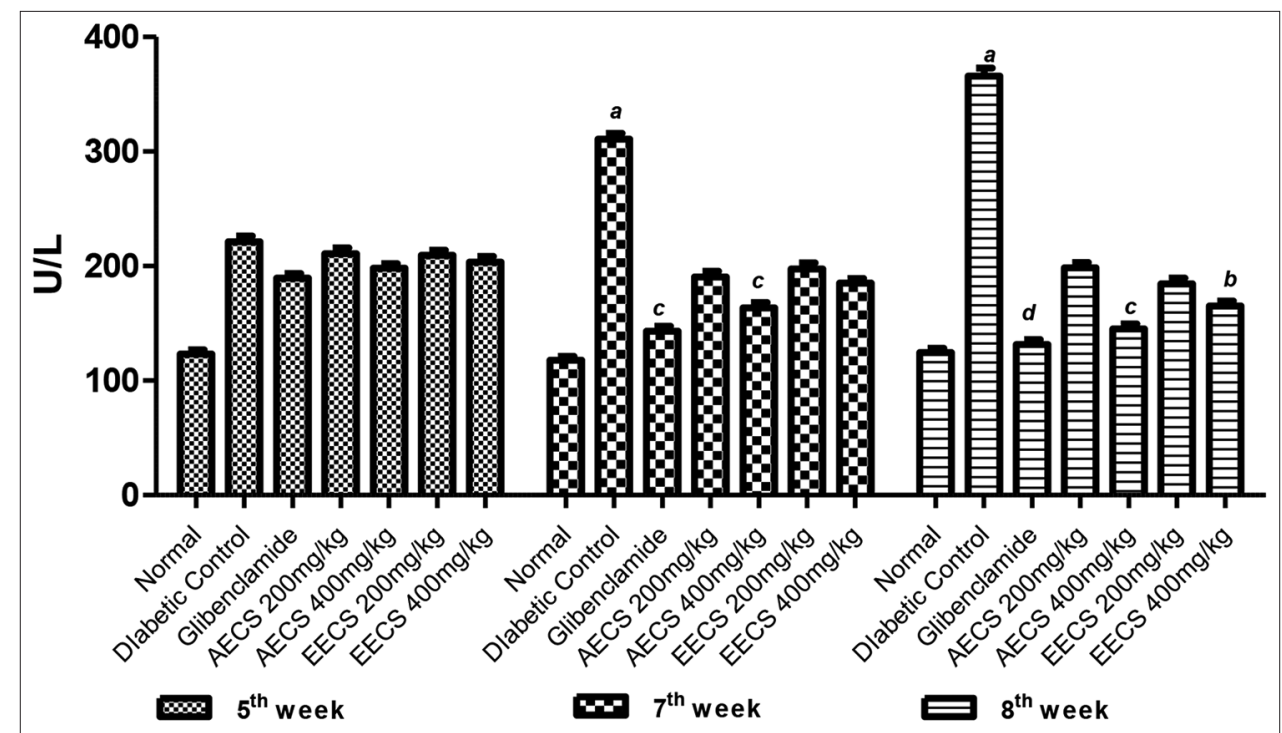

Fig. 5: Effect of plant extract on creatine kinase-myocardial band levels. $a=p<0.001$, when compared to normal (Group-I), $b=p<0.05$, when compared to control (Group-II), $\mathrm{c}=\mathrm{p}<\mathbf{0 . 0 1}$, when compared to control (Group-I), $\mathrm{d}=\mathrm{p}<\mathbf{0 . 0 0 1}$, when compared to control (Group-II)

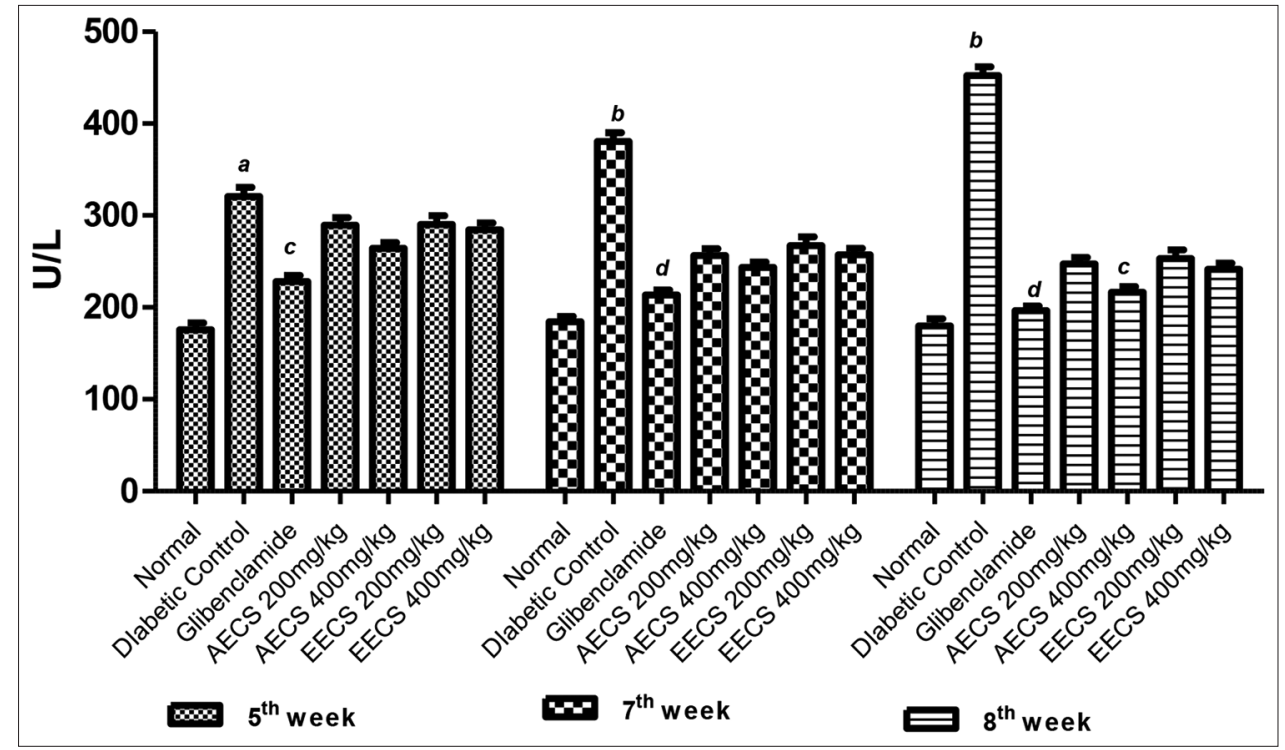

Fig. 6: Effect of plant extract on lactate dehydrogenase levels. $a=p<0.01$, when compared to normal (Group-I), $b=p<0.001$, when compared to control (Group-II), $c=p<0.01$, when compared to control (Group-I), $d=p<0.001$, when compared to control (Group-II) 


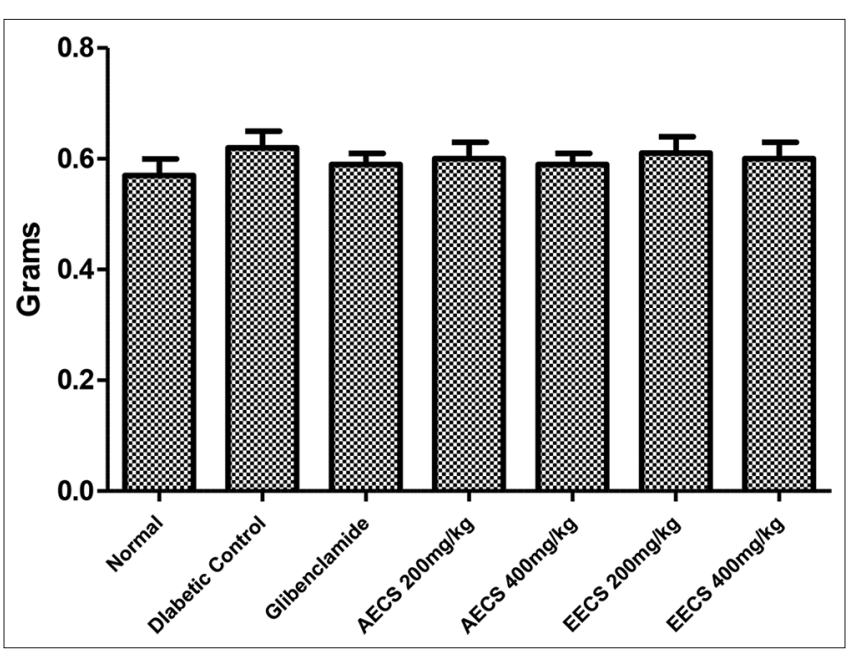

Fig. 7: Effect of plant extract on heart weight when compared to standard and test doses
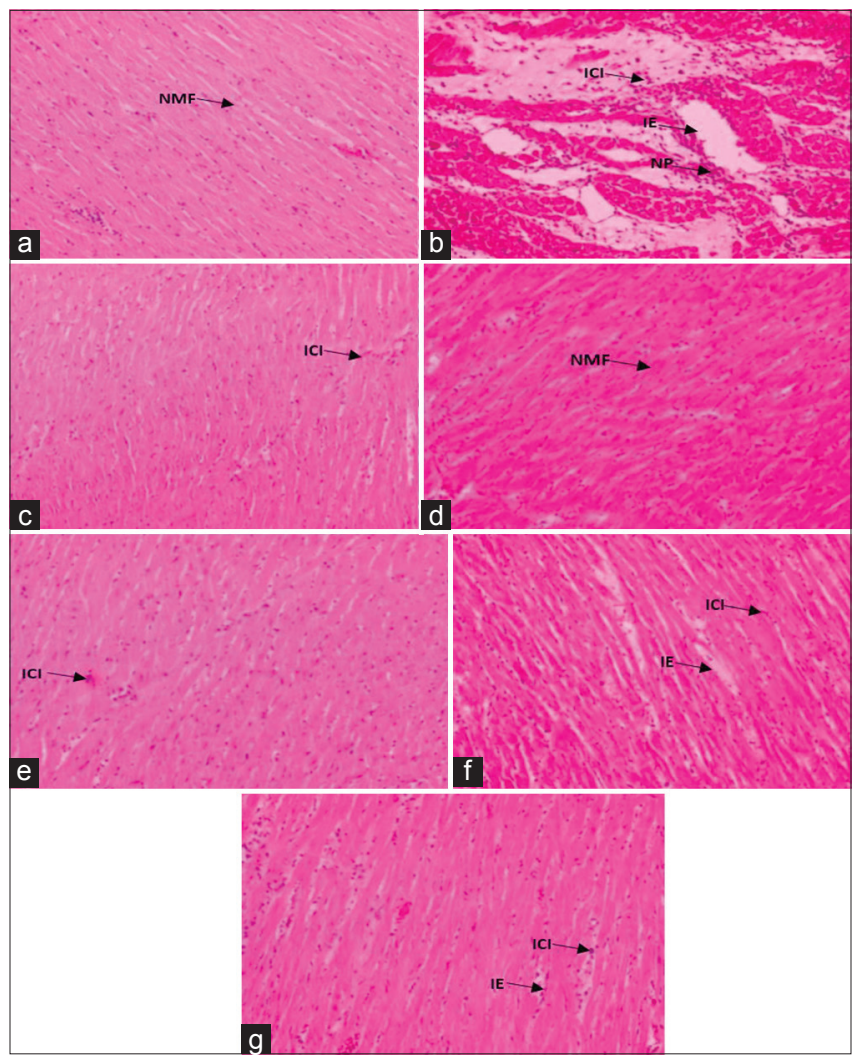

Fig. 8: Histopathological studies. (a) Group-1: Normal. (b) Group-II: Disease control. (c) Group-III: Standard (glibenclamide $5 \mathrm{mg} / \mathrm{kg}$ ) (d) Group-IV: Aqueous extract of $C$. squarrosus $200 \mathrm{mg} / \mathrm{kg}$ (e) Group-V: Ethanolic extract of $C$. squarrosus (EECS) $400 \mathrm{mg} / \mathrm{kg}$ (f) Group-VI: EECS 200 mg/kg (g) Group-VII: EECS 400 mg/kg NP: Necrotic patches, ICI: Inflammatory cell infiltration, IE: Interstitial edema

thereby potentiating the existing $\beta$-cells of the islets of Langerhans in diabetic rats [13]. In addition, the aglycone of rutin, i.e., quercetin, is reported to encourage the pancreatic islets to regenerates [14]. Insulin deficiency is also suggested to be associated with elevated cholesterol levels and hypertriglyceridemia [15]. Abnormal lipid levels contribute to diabetic patients developing coronary artery disease. The rise in serum triglycerides, cholesterol, and LDL levels in the present investigation suggests lipid metabolism derangement and increased incidence of cardiac failure in diabetics. LDH and CK levels increased which in disease control indicate cardiac muscular damage. The above studies revealed that significant rise in LDH and CK-MB levels in STZinduced diabetic rats as compared to normal group [16-18]. Treatment with AECS and EECS decreases the LDH in the diabetic rats. CK-MB levels were, however, reduced with AECS and EECS, among this aqueous extract at the dose of $400 \mathrm{mg} / \mathrm{kg} /$ day shown significant effect. Normal LDH activity is indicative of improved channeling of (pyruvate) glucose by mitochondrial oxidation. Rutin has been reported to normalize the levels of LDH and CK-MB in isoproterenol-mediated myocardial infarction in rats, cardiotoxic rats mediated by isoproterenol, and cardiotoxicity induced by doxorubicin. The result above demonstrates its cardioprotective effect that may be due to the presence of flavonoids and glycosides. Lowering the CK levels with the treatment may help prevent the progression of DCM $[19,20]$. Hence, our study exhibits $C$. squarrosus was effective agonist cardiomyopathy dose-dependent manner when it compared with disease control group, among this aqueous extract treated group (400 mg/kg) shown more significant compare with other. In histopathological studies of rat heart of normal group, minimum interstitial tissue, long spindle shaped vascular nuclei, muscle striation few small blood vessels and minimum fibro fatty tissues observed. There were no muscular hypertrophy or evidences of necrosis and/or round cell infiltrates. Streptozotocin-treated groups show muscle fibers loosely arranged with fragmentation and increased interstitial tissue, long spindle-shaped vascular nuclei with occasional large plump, whereas standard drugs and AECS (400 mg/kg) treated groups show considerable improvement, compactly arranged muscle fibers with minimum interstitial tissue, long spindle-shaped vascular nuclei, muscles striations well marked. All photomicrographs were taken on $\times 10$ and $\times 40$. Hence, our study exhibits $C$. squarrosus was effective agonist cardiomyopathy dose-dependent manner when it compared with disease control group, among this oral administration of aqueous extract $400 \mathrm{mg} / \mathrm{kg}$ shown more significant compare with other doses.

\section{CONCLUSION}

The above studies first demonstrated that $C$. squarrosus effectively inhibited hyperglycemia which may be due to presence of sufficient amounts of flavonoids. Supplementation of $C$. squarrosus decreased related inflammatory responses of the heart to provide cardioprotection in diabetic rats. AECS produces significant effect on cardiomyopathy compare with ethanolic extract.

\section{AUTHORS' CONTRIBUTIONS}

All authors are contributed equally.

\section{CONFLICTS OF INTEREST}

There are no conflicts of interest.

\section{AUTHORS' FUNDING}

No funding was provided for this research

\section{REFERENCES}

1. Bukhari SA, Shamshari WA, Rahman M, Zia-Ul-Haq M, Jaafar HZ. Computer aided screening of secreted frizzled-related protein 4 (SFRP4): A potential control for diabetes mellitus. Molecules 2014;19:10129-36

2. Available from: http://www.eatlas.idf.org

3. Bhattacharya S, Manna P, Gachhui R, Sil PC. D-Saccharic acid 1,4-lactone protects diabetic rat kidney by ameliorating hyperglycemiamediated oxidative stress and renal inflammatory cytokines via NF- $\kappa \mathrm{B}$ and PKC signaling. Toxicol Appl Pharmacol 2013;267:16-29.

4. Dewanjee S, Das AK, Sahu R, Gangopadhyay M. Antidiabetic activity of Diospyros peregrina fruit: Effect on hyperglycemia, hyperlipidemia and augmented oxidative stress in experimental Type 2 diabetes. Food Chem Toxicol 2009;47:2679-85.

5. Jinfan T, Yingke Z, Yanfei L, Yue L, Keji C, Shuzheng L. Roles and mechanisms of herbal medicine for diabetic cardiomyopathy: Current 
status and perspective. Oxid Med Cell Longev 2017;2017:8214541.

6. Babu PV, Sabitha KE, Shyamaladevi CS. Therapeutic effect of green tea extract on oxidative stress in aorta and heart of streptozotocin diabetic rats. Chem Biol Interact 2006;162:114-20.

7. Dallak M, Bashir N, Abbas M, Elassa R, Haidara M, Khalil M, et al. Concomitant down regulation of glycolytic enzymes, upregulation of gluconeogenic enzymes and potential hepato-nephroprotective effects following the chronic administration of hypoglycaemic, insulinotropic Citrullus colocynthis pulp extract. Am J Biochem Biotechnol 2009:5:153-61.

8. Bhandari U, Ansari MN. Ameliorative effect of an ethanol extract of Embelia ribes fruits on isoproterenol-induced cardiotoxicity in diabetic rats. Pharm Biol 2009;47:669-74.

9. Rajasekaran S, Sivagnanam K, Ravi K, Subramanian S. Hypoglycemic effect of Aloe vera gel on streptozotocin-induced diabetes in experimental rats. J Med Food 2004;7:61-6.

10. Das AK, Dewanjee S, Sahu R, Dua TK, Gangopadhyay M, Sinha MK. Protective effect of Corchorus olitorius leaves against arsenic-induced oxidative stress in rat brain. Environ Toxicol Pharmacol 2010;29:64-9.

11. Pelter A, Ward RS, Rao EV, Raju NR. 8-substituted flavonoids and 3'-substituted 7-oxygenated chalcones from Tephrosia purpurea. J Chem Soc Perkin Trans 1 1981;1:2491-8.

12. Sarkhail P, Rahmanipour S, Fadyevatan S, Mohammadirad A, Dehghan G, Amin G, et al. Antidiabetic effect of Phlomis anisodonta: Effects on hepatic cells lipid peroxidation and antioxidant enzymes in experimental diabetes. Pharmacol Res 2007;56:261-6.
13. Naik SR, Barbosa Filho JM, Dhuley JN, Deshmukh V. Probable mechanism of hypoglycemic activity of bassic acid, a natural product isolated from Bumelia sartorum. J Ethnopharmacol 1991;33:37-44.

14. Kamalakkannan N, Prince PS. Antihyperglycaemic and antioxidant effect of rutin, a polyphenolic flavonoid, in streptozotocin-induced diabetic wistar rats. Basic Clin Pharmacol Toxicol 2006;98:97-103.

15. Vessal M, Hemmati M, Vasei M. Antidiabetic effects of quercetin in streptozocin-induced diabetic rats. Comp Biochem Physiol C Toxicol Pharmacol 2003;135C:357-64.

16. Bhadada SV, Goyal RK. Comparative evaluation of atenolol and metoprolol on cardiovascular complications associated with streptozotocin-induced diabetic rats. Can J Physiol Pharmacol 2007;85:831-6.

17. Shamim A, Mahmood T, Mukeem M, Siddiqui HH, Bagga P, Firdaus H, et al. Effect of ethanolic extract of Glycyrizza glabra against streptozotocin and high-fat diet-induced diabetes and hyperlipidemia. Int J Pharm Pharm Sci 2016;8:259-66.

18. Devi S, Singh R. Antidiabetic activity of methanolic extract of Nepeta hindostana herb in streptozotocin induced diabetes in rats. Int J Pharm Pharm Sci 2016:8:330-5

19. Hozayen WG, Abou Seif HS. Protective effects of rutin and hesperidin against doxorubicin-induced lipodystrophy and cardiotoxicity in albino rats. J Am Sci 2011;7:765-75.

20. Matsumoto Y, Kaneko M, Kobayashi A, Fujise Y, Yamazaki N. Creatine kinase kinetics in diabetic cardiomyopathy. Am J Physiol $1995 ; 268: 1070-6$ 